\title{
PSICOLOGIA, ÉTICA E BIOÉTICA
}

\author{
Psychology, Ethics and Bioethics
}

\author{
Kleber Prado Filho ${ }^{1}$ \\ Sabrina Trisotto ${ }^{2}$
}

\section{Resumo}

Este texto reproduz uma comunicação realizada em uma mesa-redonda intitulada "Psicologia e ética: qual a relação entre a psicologia e o problema da bioética?", que teve lugar na "Semana de Psicologia" promovida pela Universidade Federal de Santa Catarina em Novembro de 2003, e apresenta uma reflexão a respeito das relações entre a prática psicológica, as questões de ordem ética e a problemática contemporânea da bioética. Aponta as estreitas relações entre a ética médica e a da psicologia, destacando a centralidade de valores humanitários comuns à ética dos psicólogos e à bioética - normatividade oriunda dos domínios da medicina e da biologia - que estende aos animais e à própria natureza procedimentos e cuidados anteriormente aplicados exclusivamente aos humanos.

Palavras-chave: Psicologia; Ética; Bioética.

\section{Abstract}

The present text reproduces a communication carried through on a debate entitled "Psychology and ethics: what is the relation between psychology and the bioethics issue?" - which took place in the "Psychology Week", promoted by Universidade Federal de Santa Catarina, in November, 2003 - and presents a reflection regarding the relations between psychological practice, ethical issues and contemporary problems involving bioethics. It points to the close relation between medical and psychological ethics, stressing the centrality of common humanitarian values shared by the psychologist's ethics and bioethics - normativity originated in the domains of medicine and biology - which extends to animals and nature itself some procedures and concerns that used to be directed exclusively at humans.

Keywords: Psychology; Ethics; Bioethics.

1 Psicólogo pela PUC/MG, Doutor em Sociologia pela USP, Pós-Doutor em História, Professor do Dept. de Psicologia da UFSC.

2 Psicóloga e Mestre em Educação pela UFSC, responsável pela transcrição, digitação e edição do material.

Endereço para contato: Caixa Postal 5068 - Trindade - CEP: 88040-970 - Florianópolis/SC.

E-mail: kprado@brturbo.com.br 
As ligações entre a Psicologia e a problemática da Ética são bem anteriores à questão da ética profissional no campo de exercício das práticas psicológicas e passam, antes de tudo, pelo problema da conduta.

Como ciência que se dedica, entre outras coisas, ao estudo dos comportamentos, a Psicologia deve ocupar-se também deste tipo especial de comportamento que é a conduta, porque, do ponto de vista conceitual - apesar das semelhanças e confusões - comportamento é diferente de conduta. Enquanto o comportamento como problema psicológico é considerado algo relativamente livre e individualmente motivado, a conduta encontrase referida a valores e normas, colocando-se na condição de comportamento pautado por princípios, onde a moralidade e normatividade sociais as instâncias dos códigos - fazem seu trabalho e mostram sua força.

A conduta ética é um tipo particular de comportamento orientado por preceitos, que apresenta dimensões individuais e coletivas, implicando questões políticas, uma vez que coloca em jogo um sujeito que toma decisões dentro de uma estreita faixa definida por limites e padrões socialmente estabelecidos. Isto pressupõe um sujeito racional, consciente e reflexivo - sujeito kantiano, moderno - que exerce sua liberdade e autonomia para decidir, tendo em conta seus limites e responsabilidades sociais, avaliando as conseqüências dos seus atos.

Equivale a dizer que não somos totalmente livres em termos do exercício da nossa individualidade, da nossa subjetividade, dos nossos desejos e singularidades, fazendo-se necessário - voluntariamente - reconhecer limites e avaliar conseqüências. Isto aponta para a necessidade de um governo do sujeito por si mesmo, de um exercício de autonomia, que implica trabalhar-se.

Então, além de um problema de poder, temos aí também uma questão estética: uma necessidade de estetizar nossa conduta realizando um trabalho sobre nós mesmos no sentido de tornar possível a convivência social, ao mesmo tempo em que nos produzimos mais "agradáveis" aos olhos dos outros. Nós ocidentais modernos somos herdeiros da tradição ética grega da estética da existência, que coloca uma necessidade que é quase uma obrigação, de realizar um trabalho de estetização da conduta individual, como condição de exercício da cidadania. Somos, também, herdeiros da tradição romana do governo e cuidado por nós mesmos, além de debitários da ética racionalista kantiana, historicamente mais próxima de nós.

E tudo isso tem muito a ver com a Psicologia: a questão da conduta, este governo de si por si mesmo, este trabalho sobre si, esta produção de si mesmo, esta estética da existência, este cuidado de $\mathrm{si}^{3}$.

Passando agora à questão profissional - quais as ligações entre Psicologia e Ética?

Penso, inicialmente, serem relações da maior importância, uma vez que a Psicologia é a disciplina científica que se ocupa do homem concreto - o sujeito constituído nas suas relações com a natureza, com as coisas, com os signos, símbolos, regras, normas, com os outros homens, e consigo mesmos - dedica-se a ele e, talvez, por isso mesmo, deva ser a mais humana de todas as Ciências Humanas.

Atendendo a este compromisso fundamental, a ética da Psicologia é centralmente humanista, apoiada em valores de respeito, dignificação e defesa do ser humano. Mas ela é também - imediatamente - uma ética política que implica compromissos e posturas. Porque a Psicologia, ao mesmo tempo em que se dedica ao homem, acaba tomando-o por objeto do seu olhar e das suas práticas, exercendo quotidianamente poderes efetivos sobre ele. E é justamente porque a Psicologia é um conjunto - mesmo que não unitário - de saberes e práticas políticas sobre os sujeitos, que ela precisa de uma ética pautada em princípios humanistas para colocar limites ao seu exercício de poder. Ela não pode ser apenas técnica aplicação de uma tecnologia humana - tampouco pode ser mero exercício de saber/poder sobre os sujeitos: ela precisa de um conjunto de valores e preceitos - de uma ética - para limitar seus poderes e nortear suas variadas práticas exercidas pelos psicólogos em diversos campos profissionais.

3 Nos volumes II e III da sua "História da Sexualidade", Michel Foucault apresenta as experiências éticas grega e romana da cultura Antiga, caracterizadas respectivamente como "estética da existência" e "cuidado de si", das quais nós ocidentais contemporâneos somos debitários, além, evidentemente, das influências da ética medieval cristã - reativa - e do racionalismo, utilitarismo e individualismo característicos da ética moderna. 
A ética da Psicologia apresenta, ainda, grande proximidade e afinidade com uma ética biologicista, médica, do campo da saúde. Tratase - como neste campo - de uma ética de cuidado pelo outro, correlativa das "profissões de cuidado", ligada ao modelo confessional do consultório médico - que é totalmente atravessado pelo problema do sigilo - posta em estreita relação com a problemática da norma: definição de faixas de normalidade, suas fronteiras e limites; poder discursivo-institucional de enunciar a normalidade dos sujeitos; poder de reconduzir os sujeitos à faixa de normalidade, de reeducá-los. Devese lembrar que a Psicologia, ao lado da Psicanálise e da Psiquiatria, compõe um conjunto de ciências socialmente reconhecidas e autorizadas a enunciar a normalidade dos sujeitos, bem como intervir sobre estes sujeitos a partir do conhecimento que se tem a respeito da sua posição em relação à norma.

Tudo isso que foi dito coloca uma necessidade de estetização da conduta técnico/ético/política do psicólogo - um trabalho do profissional sobre si mesmo no sentido de dosar o exercício de poder decorrente da aplicação dos seus conceitos e instrumental técnico, e de buscar modos de relação ética e respeitosa com o sujeito de suas intervenções e procedimentos. Não é suficiente conhecer conceitos, como não é suficiente saber aplicar instrumentos e técnicas psicológicas, é necessário ser um profissional mais amplo, capaz de transitar de forma crítica por meio destas embricadas dimensões técnico-ético-políticas da atuação profissional dos psicólogos.

E isto coloca de forma imediata o problema da formação profissional do psicólogo, que se encontra na base de tudo isso. Os cursos de psicologia não podem limitar-se a ensinar conceitos e reproduzir teorias, como não é suficiente instrumentalizar pragmaticamente o futuro psicólogo para aplicação da tecnologia psicológica - é necessário ultrapassar a dicotomia teórico-prática, mas não podemos nos contentar com esta tão propalada e nunca alcançada integração teoria x prática é preciso ir mais longe: faz-se necessário trabalhar a conduta ética e no mesmo movimento desenvolver posturas políticas adequadas a um exercício profissional consciente e conseqüente por parte da categoria. Este é, portanto, um compromisso social da Psicologia como profissão que deve começar a ser alinhavado nas salas de aula!
No que diz respeito às relações com a Bioética gostanímos de pontuar algumas questões. Apesar desta forma de normatividade ganhar visibilidade no Brasil apenas na última década do Século XX, ela surge nos Estados Unidos e Europa nos anos 1960 no bojo de uma acentuação em termos da exigência de maior nível de eticidade no campo dos negócios e das relações com a natureza, no entanto, o termo ganha reconhecimento internacional somente em 1971, numa publicação do cancerologista Van Rensselaer Potter.

O neologismo "bioética" sugere uma normatividade centrada no valor fundamental da vida que, a exemplo da ética no campo das práticas psicológicas, encontra-se imediatamente ligada à ética médica - porém não se restringindo a esta com fortes e visíveis componentes de ordem humanitária. Caracteriza-se por princípios da tolerância e pluralismo de valores, estendendo aos animais e à própria natureza preceitos e procedimentos anteriormente aplicados no trato exclusivo com os humanos - ela representa, assim, uma humanização ética em sentido bem amplo.

De forma mais específica, orienta-se conforme enunciados de autonomia, beneficência, nãomaleficência e justiça. $\mathrm{O}$ atendimento ao primeiro preceito aponta para a necessidade de respeito à autonomia e liberdade dos seres vivos - não apenas humanos - envolvidos em procedimentos profissionais. Esta obrigatoriedade contemporânea de apresentação do diagnóstico médico ao paciente e sua família decorre da aplicação deste enunciado. Os princípios de beneficência e não-maleficência encontram-se intimamente relacionados, implicando cuidados no sentido de garantir conforto e evitar prejuízos desnecessários aos sujeitos atingidos por práticas profissionais. Já o último preceito coloca a obrigatoriedade de um tratamento profissional justo em relação aos sujeitos envolvidos.

Vale lembrar que as preocupações bioéticas não se encontram inscritas no registro moral e maniqueísta de uma luta entre "bem x mal" elas voltam-se para a formação de um comportamento socialmente responsável por parte daqueles que têm o poder profissional de decidir e agir sobre a vida de outros seres vivos, deslocando o centro destas decisões e ações do domínio de uma racionalidade instrumental objetivante, para levar em conta aspectos de subjetividade e singularidade. Portanto, tais preocupações se inscrevem num 
horizonte profissional multidisciplinar, não se restringindo aos campos das ciências médicas, biológicas e psicológicas, mas estendendo-se aos domínios da Filosofia, da Antropologia, da Sociologia, do Direito, da Economia e das Ciências Políticas, entre outras.

Particularmente no Brasil esta normatividade emergente tem produzido sensíveis efeitos no âmbito da pesquisa científica - que equivocadamente entre nós confina-se nos espaços universitários - colocando limites mais estreitos à experimentação com sujeitos humanos e à utilização de animais ou mesmo recursos naturais a título de produção de conhecimento. Ela joga por terra esta perigosa crença - hoje ultrapassada - de que "tudo se justifica em nome da ciência". Assim, ao submeter um protocolo de pesquisa à aprovação de uma comissão que o analisa, a Bioética retira a investigação científica do ambiente isolado e protegido dos laboratórios expondo esta prática à validação social, porque a ciência não pode ser ao mesmo tempo a única barreira posta por e para si mesma.
Os recentes desenvolvimentos tecnológicos no campo da biologia molecular, inadequadamente denominada "engenharia genética" - projeto genoma, clonagem, alimentos transgênicos mostram, neste século que apenas se anuncia, os riscos de uma manipulação irresponsável da vida, justificando a necessidade de uma ética reguladora de tais procedimentos em escala planetária e multiprofissional.

\section{Referências}

Foucault, M. (1989). História da sexualidade III: O cuidado de si. Rio de Janeiro: Graal.

\section{Foucault, M. (1989). História da sexualidade II:} O uso dos prazeres. Rio de Janeiro: Graal,

Recebido em/Received in: 18/05/2006 Aprovado em/Approved in: 28/05/2006 